\title{
Seed storage importance and behaviour of a vulnerable species Angsana (Pterocarpus indicus Willd.)
}

\author{
Ridesti Rindyastuti ${ }^{1 *}$, Febrina Artauli Siahaan ${ }^{1}$ \\ ${ }^{1}$ Purwodadi Botanic Garden, Research Centre for Plant Conservation and Botanic Gardens -Indonesian Institute of Sciences \\ J1. Raya Surabaya-Malang, Km. 65, Purwodadi, Pasuruan 67163, East Java, Indonesia
}

\begin{abstract}
Angsana (Pterocarpus indicus Willd.) is one of woody plant species listed in the IUCN red list for priority in conservation as a vulnerable species. The effective and low-cost methods of seed storage is required to support the ex-situ conservation through seedling recruitments for population improvement. This study used completely randomized factorial design with 2 factors i.e. seed storage methods (room temperature, sealed jar and cold temperature), and storage duration (1,2,3,4 and 5 months). This study used 3 replications for each treatments and 10 seeds for each replication. The result showed that the seed of $P$. indicus start to germinate in 5-11 days after seeding while leaf emerged in 15-13 days after seeding. Seed viabilities generally were high until 3 months of storage (up to 65\%) and start to decline at 4 months of storage at $51 \%$. Storage methods and storage duration significantly influenced the seedling growth, viability, and Relative Growth Rate (RGR). There was an interaction between two factors. The storage at room temperature during a month (1RT) has the highest seedling height. The seeds stored in sealed jar during 5 months (5SJ) showed the highest seedling RGR, while the seeds stored in sealed jar during 3 months (3SJ) has the highest seed viability. For longer term storage, the seed of $P$. indicus should be stored in sealed jar or at room temperature at $11 \%$ moisture content. Both in the rainy and dry season, seedling recruitments were low and sapling stage was rare which showed low seedling establishment. Moreover, based on the phenological information, it is better to store the seed during the rainy season.
\end{abstract}

Keywords: Duration, methods, seed, storage, Pterocarpus indicus

Received: 20 April 2018 Revised: 11 April 2019 Accepted: 02 June 2019

\section{Introduction}

Pterocarpus indicus which has the local name of red wood, angsana or sonokembang belongs to Leguminosae family. Angsana is a deciduous large tree, moderately fast growing plant and widely distributed throughout the tropics, from southern Myanmar to the Philippines and throughout the Malay Archipelago to New Guinea and the Solomon Islands. P. indicus is multipurpose source of timber and medicine. $P$. indicus is well-adapted to strong wind but is not well-adapted to poor fertility. It fixes nitrogen but is likely to grow slowly and show lower timber production if grow in less fertile soil. Population in its several range of distribution decline in recent years because of over exploitation. Thus, this species is listed in IUCN red list for priority in conservation program as a vulnerable species (Thomsom, 2006; Orwa et al., 2009).

The threat of extinction of $P$. indicus did not come only from external aspect such as exploitation. Intrinsic factors such as reproductive barrier and low adaptation ability treat greatly this species. $P$. indicus has fruit type namely samara which is a nut-like, hard pericarp and perifery winged. There is only one seed in one fruit but sometimes more (1$3)$. As seed of $P$. indicus is a winged seed, it is dispersed by wind. Fruit wing of $P$. indicus is not open during seed dispersal and it causes the seed mechanically dormant

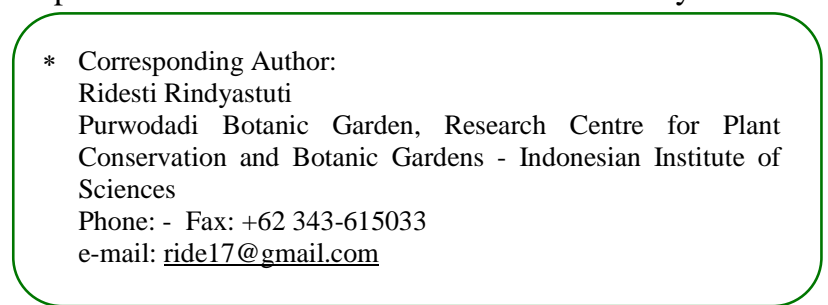

beside of hard fruit and pericarp. P. indicus has short flowering cycle that only occurs in 1-2 days in the 5-7 days of intervals during 1-2 months of flowering cycle. The seed mature 3-5 months after flowering and mechanically dormant (Schmidt, 2000).

Seed storage is one of effective ex-situ method to preserve plant genetic variability that support in-situ conservation. It is useful in supporting ex-situ seed bank because, even short-term seed banking, could increase seedling recruitment and affect population dynamics of trees. Seed are needed to be preserved to rescue genetic variability, avoid genetic errosion and inbreeding depression especially for species with small population (Guerrant et al., 2004). The most suitable long term storage method for $P$. indicus is to store de-winged fruits in low temperature and moisture. Seeds are distinguished between the seeds that adapted to tropical environment and adapted to temperate environment (Hong et al., 1998). For practical method storage in conservation program, the storage method information should be more detail, simple and applicable to distribution region of plant species especially in the tropic, based on the effective and low cost consideration (Thomsom, 2006).

The storage method would benefit greatly if a species is rare and threatened mainly because of reproductive barrier in the nature. Reproductive barrier may create very small new populations and magnify the possibility of species extinction. Reproductive biology of threatened taxa can be identified through investigation of seedling recruitment in the forest floor under the tree stands to understand the capability of species to regenerate in its population (Eriksson \& Ehrlén, 2008). Thus, here we 
addressed the objectives of this study, 1) to study the seed characters of one of $P$. indicus varieties collected by Purwodadi Botanic Garden, 2) to emphasize the benefit methods of seed storage related to temperature and seed

\section{Methods}

\section{Seed Characters}

Phenology of $P$. indicus were trajectorily studied during 5 years (from 2007-2012). Reproductive biology were observed through morphological observation in Purwodadi Botanic Garden and literature study. Seed morphology characters of $P$. indicus were observed quantitatively by measured the seed size and weight, while the color character was observed directly from the mature seed. The data of seed production of $P$. indicus was collected from Purwodadi Botanic Garden collection and database in Registration Unit. The seed germination behaviour of $P$. indicus were observed in each stage of germination from the seedling initiation until new shoots emergence. The germination type and time were observed and noted.

\section{Seed Storage Behaviour: the Effects of Seed Storage to} Seedling Growth, Seed Viability and Seedling RGRs

Fruit of $P$. indicus were harvested in April 2016. Seeds were obtained after extraction proccess which is required to release seeds from hard pericarp. Special pre-treatment of fruits and seeds is not necessary for this species. Seeds were kept in a closed alumunium bag for all storage methods with the moisture content around $10-12.5 \%$. Seeds of $P$. indicus in alumunium bag were stored in three methods: 1) room temperature $\left.\left(22^{\circ} \mathrm{C}\right) 2\right)$ cold temperature $\left(-15^{\circ} \mathrm{C}\right.$ ) and 3$)$ sealed jar (at room temperature). The seeds were stored in 5 months then were germinated in sand media in month of 1, 2, 3, 4 and 5. Seed longevity after storage were observed through comparison among three parameters i.e. seedling viability, seedling height and Relative Growth Rates (RGRs) in different storage methods.

RGR was calculated using the following equation (Hoffmann \& Poorter, 2002) :

\section{Results}

\section{Fruit and Seed Phenology of $P$. indicus}

Seed storage is absolutely needed by the plant species which 1) has low seed productivity, 2) plant do not yield fruits regularly 3) has a long fruiting interval 4) fruiting periode occur after seeding season (Schmidt, 2000). The seed production of $P$. indicus was low. It can be harvested approximatelly 100 seeds per plant every months. However, this species yield fruit regularly, during about 4 months each years. The fruit interval is not too long however fruiting period occurs before seeding period (during the dry season) (pers. interview).

\section{Seed Characters}

\section{Seed Morphology}

Fruit type of $P$. indicus namely samara which is a nutlike, hard pericarp and perifery winged. Seed morphology humidity to seedling growth, seed viability and seedling RGRs of $P$. indicus and 3 ) to reveal the importance of seed storage based on the comparison of the seedling recuitment of $P$. indicus among other plant species.

Where:

$$
\mathrm{RGR}=\left(\ln \mathrm{W}_{2}-\ln \mathrm{W}_{1}\right) /\left(\mathrm{t}_{2}-\mathrm{t}_{1}\right)
$$

$$
\begin{aligned}
& \ln =\text { natural logaritm } \\
& \mathrm{t}_{1}=\text { time one } \\
& \mathrm{t}_{2}=\text { time two } \\
& \mathrm{W}_{1}=\text { dry weight of plant in time } 1 \\
& \mathrm{~W}_{2}=\text { dry weight of plant in time } 2
\end{aligned}
$$

\section{Seed Storage Importance of $\boldsymbol{P}$. indicus}

Seed storage importance of $P$. indicus were studied by investigating the seedling recruitment. Seedling recruitment was investigated by analyzing the ground cover vegetation using sampling method in plot of $10 \times 10$ $\mathrm{m}$ under the tree stands. The site study were located in Purwodadi Botanic Garden-LIPI, Pasuruan, East Java Province. The garden has the range of temperature of 22$32^{\circ} \mathrm{C}$. This study was established on both rainy (November 2016) and dry season (April 2017). The distance among the sampling plots was determined by considering the wingedfruit that has an ability of being dispersed far from the tree stands by wind. The seedling were sampled in 3 locations (vak IX F, XVI H and XXIII H). Five plots of $1 \mathrm{x} 1 \mathrm{~m}$ which placed under the tree stands of $P$. indicus were used to record the number of seedling in each location.

The importance of seed storage was also investigated through descriptive comparison of the number of seedling and the coverage presentage between seed in natural population and those of other species based on the previous study. The analysis of seed storage importance was established through study and comparison among the seed aspects such as phenology, reproductive biology, seed morphology, seedling recruitment and the viability of stored seed.

of $P$. indicus is explained in several characters of extracted seed such as seed shape, color, size and weight. The shape seeds of $P$. indicus is elipsoid with an acute tip. It is light until dark brown and sometimes reddish brown colored (Fig. 1). The average of seed size is $10.73 \mathrm{~mm}$ long and $4.85 \mathrm{~mm}$ wide. The average of seed weight is $0.079 \mathrm{~g}$.

\section{Seed Production}

The data of seed production of $P$. indicus was collected from Purwodadi Botanic Garden plant collection and database of annual fruit and seed production. The data of annual fruit and seed production were recorded during 5 years (from 2007-2012). Thehigher seed quantities were occured in months 3 to 8 every year. 


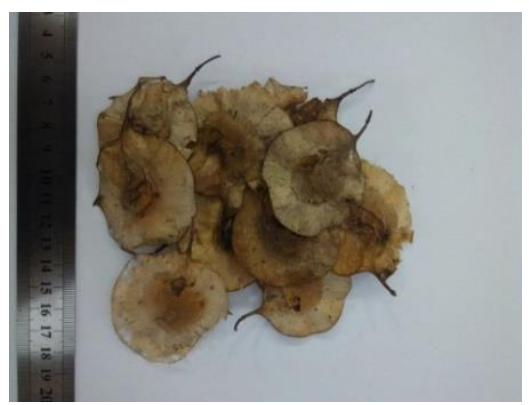

(a)

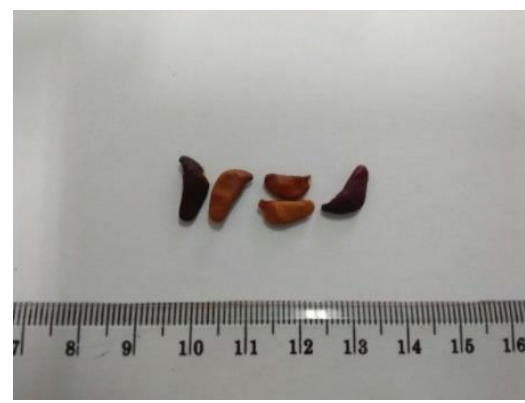

(b)

Figure 1. (a) The intact fruit of $P$. indicus, consist of wing and hard pericarp (b) extracted seed of $P$. indicus.

Table 1. Annual fruit and seed production of $P$. indicus collected in Purwodadi Botanic Garden. Month

\begin{tabular}{llllllllllll}
\hline 1 & 2 & 3 & 4 & 5 & 6 & 7 & 8 & 9 & 10 & 11 & 12
\end{tabular}

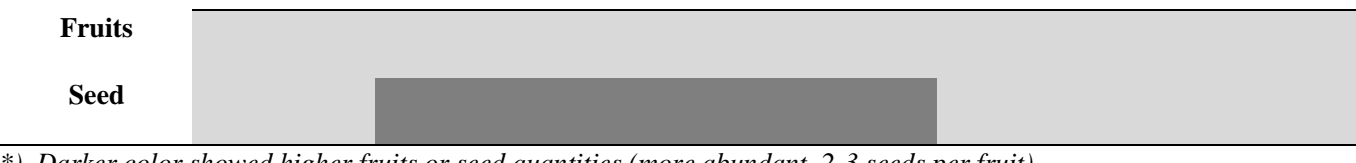

*) Darker color showed higher fruits or seed quantities (more abundant, 2-3 seeds per fruit).

Table 2. Seed germination behavior of $P$. indicus using three replications.

\begin{tabular}{|c|c|c|c|c|c|c|c|c|c|c|c|}
\hline \multirow{2}{*}{ No. } & \multirow{2}{*}{ Seedling growth characters } & \multicolumn{3}{|c|}{ Replication-1 (day) } & \multicolumn{3}{|c|}{ Replication-2 (day) } & \multicolumn{3}{|c|}{ Replication-3 (day) } & \multirow{2}{*}{ Range (day) } \\
\hline & & 1 & 2 & 3 & 1 & 2 & 3 & 1 & 2 & 3 & \\
\hline 1. & Seedling initiation & 7 & 10 & 5 & 8 & 7 & 11 & 5 & 7 & 11 & $5-11$ \\
\hline 2. & Cotyledon emergence & 8 & 11 & 7 & 10 & 8 & 12 & 6 & 8 & 13 & $6-13$ \\
\hline 3. & Seed coat removal & 10 & 12 & 9 & 12 & 9 & 13 & 8 & 9 & 14 & $8-14$ \\
\hline 4. & Cotiledon cleveage/ leaf emergence & 15 & 17 & 15 & 17 & 15 & 18 & 15 & 15 & 18 & $15-18$ \\
\hline 5. & Epicotyl senescense & 52 & 52 & 52 & 52 & 52 & 52 & 52 & 52 & 52 & 52 \\
\hline 6. & New shoots emergence & 19 & 19 & 19 & 19 & 19 & 19 & 12 & 19 & 19 & $12-19$ \\
\hline
\end{tabular}

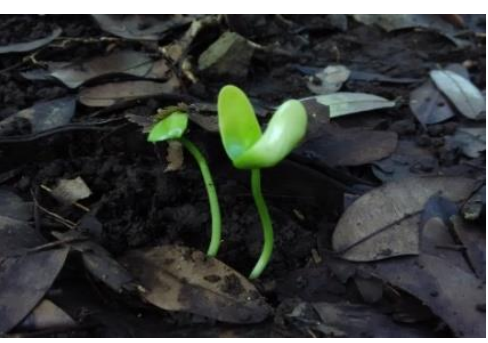

(a)

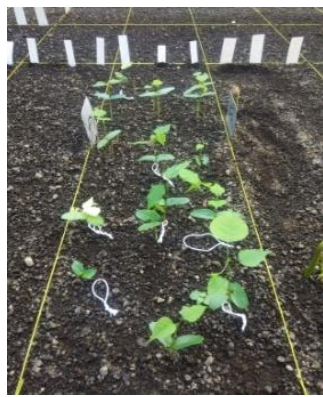

(b)

Figure 2. The germination of $P$. indicus. a) an epigeal germination b) the seedling growth from seedling initiation to shoots emergence.

Table 3. Moisture content (\%) of $P$. indicus seed used in this study during the experiments.

\begin{tabular}{lccccc}
\hline \multicolumn{1}{c}{ Storage methods } & \multicolumn{5}{c}{ Duration } \\
\cline { 2 - 6 } & Fresh & $\mathbf{1}$ & $\mathbf{2}$ & $\mathbf{3}$ & $\mathbf{4}$ \\
\hline Room temperature (RT) & 12.39 & 10.93 & 10.90 & 10.90 & 10.68 \\
Cold temperature (CT) & 12.43 & 11.76 & 11.92 & 11.22 & 10.85 \\
Sealed Jar (SJ) & 12.40 & 12.39 & 12.40 & 12.38 & 12.11 \\
\hline
\end{tabular}

Table 4. The significance of storage methods and storage durations to the seedling height, viability and RGRs showed by $\mathrm{P}$ value $(\mathrm{P}<0.05)$. $*$ Showed interaction between storage methods and storage durations.

\begin{tabular}{lccc}
\hline \multicolumn{1}{c}{ Treatments } & Seedling Height & Viability & RGRs \\
\hline Storage methods & 0.011 & 0.0000 & 0.000 \\
Storage durations & 0.038 & 0.00037 & 0.0004 \\
Storage methods* Storage durations & 0.025 & 0.0000 & 0.000 \\
\hline
\end{tabular}




\section{Seed Germination Behaviour}

The seed of $P$. indicus germinated in 5-11 days after seeding. The germination type of this species is epigeal because the cotyledon emerge to the above soil surface, thus the cotyledon serves as an epicotyl (Fig. 2). The cotyledon emerged in 6-13 days after seeding. The seed released its seed coat in 8-14 days after seeding. The leaf start to emerge or cotyledon start to cleveage in around 1518 days. The seedling started to have new shoots in 12-19 days. The epicotyl is considered to become photosynthetic leaf to support the seedling in long term until 52 days after seeding (Table 2).

According to Orwa et al. (2009), the seeds are difficult to extract, but will germinate readily through built-in weaknesses in the fruit wall. Therefore, there is no special advantage of extracting the seeds because the germination time and percentage are practically similar between whole fruits and extracted seeds. Thus, the seeds can be stored both in a whole fruit and extracted seeds. However, the seeds are commonly stored as de-winged seeds (whole form, without seed extraction) (Thomsom, 2006; Schmidt, 2000). To store thefruit in the whole form will take more space both when it is stored and germinated. However, to extract the the seed is time consuming as well and resulting in uneffective seed storage. Contrary, in seed storage, the seeds number and quality should be considered by observing the morphology of extracted seed. Thus, for storage effectiveness, this could be advantageous to store the seed in extracted form than in intact or whole fruit.

According to Thomsom (2006), seed of P. indicus is orthodox, being able to be dried down to $4 \%$ moisture content from initial content around $16-17 \%$. The seed used in this study are still various in moisture content, ranging from $10-12.5 \%$. The moisture content of stored seed of $P$. indicus during the experiment were presented in Table 3.

The moisture content of fresh seed of $P$. indicus was about $12.4 \%$ then decline until 10.45 to $11.48 \%$. The moisture content of seed stored at room temperature declined during the storage period from $12.5 \%$ to $10 \%$ in month 2, while the moisture content of seed stored in sealed jar declined to $11.48 \%$ in month 4 . Seed stored at cold temperature have the moisture content which decline sharply from $12.43 \%$ to $10.11 \%$. It showed that the moisture content reductions in sealed jar was gradual while in cold temperature and room temperature were sharp.

Table 5. Seedling height, viability and RGRs of $P$. indicus in various storage methods and storage durations.

\begin{tabular}{|c|c|c|c|c|}
\hline Storage methods & $\begin{array}{c}\text { Months (storage } \\
\text { durations) }\end{array}$ & Seedling Height (cm) & Seed viability $(\%)$ & $\begin{array}{c}\text { RGRs } \\
\left(\mathrm{g} \mathrm{g}^{-1} \text { day }^{-1}\right)\end{array}$ \\
\hline \multirow[t]{5}{*}{ Room Temperature $(\mathrm{RT})^{\mathrm{a}}$} & 1 & $12.78^{\mathrm{a}}$ & $80^{\mathrm{ab}}$ & $0.0189^{\mathrm{bc}}$ \\
\hline & 2 & $12.18^{\mathrm{a}}$ & $66.67^{\mathrm{ab}}$ & $0.025^{\mathrm{abc}}$ \\
\hline & 3 & $10.64^{\mathrm{ab}}$ & $56.67^{\mathrm{ab}}$ & $0.0285^{\mathrm{ab}}$ \\
\hline & 4 & $8.75^{\mathrm{ab}}$ & $53.33^{\mathrm{b}}$ & $0.0288^{\mathrm{ab}}$ \\
\hline & 5 & $7.77^{\mathrm{ab}}$ & $66.67^{\mathrm{ab}}$ & $0.0268^{\mathrm{abc}}$ \\
\hline \multirow{5}{*}{ Cold Temperature $(\mathrm{CT})^{\mathrm{b}}$} & 1 & $12.18^{\mathrm{a}}$ & $50^{\mathrm{b}}$ & $0.0075^{\mathrm{c}}$ \\
\hline & 2 & $10.43^{\mathrm{ab}}$ & $73.33^{\mathrm{ab}}$ & $0.007^{c}$ \\
\hline & 3 & $11.3^{\mathrm{a}}$ & $66.67^{\mathrm{ab}}$ & $0.0085^{\text {bc }}$ \\
\hline & 4 & $9.12^{\mathrm{ab}}$ & $56.67^{\mathrm{ab}}$ & $0.012^{\mathrm{bc}}$ \\
\hline & 5 & $9.29^{\mathrm{ab}}$ & $70^{\mathrm{ab}}$ & $0.0176^{\mathrm{bc}}$ \\
\hline \multirow[t]{5}{*}{ Sealed Jar $(\mathbf{S J})^{\mathbf{c}}$} & 1 & $7.02^{\mathrm{ab}}$ & $60^{\mathrm{ab}}$ & $0.0091^{\mathrm{bc}}$ \\
\hline & 2 & $11.25^{\mathrm{a}}$ & $80^{\mathrm{ab}}$ & $0.0118^{\mathrm{bc}}$ \\
\hline & 3 & $5.52^{\mathrm{b}}$ & $93.33^{\mathrm{a}}$ & $0.0184^{\mathrm{bc}}$ \\
\hline & 4 & $9.49^{\mathrm{ab}}$ & $43.33^{\mathrm{b}}$ & $0.028^{\mathrm{ab}}$ \\
\hline & 5 & $8.53^{\mathrm{ab}}$ & $56.67^{\mathrm{ab}}$ & $0.0423^{\mathrm{a}}$ \\
\hline Fresh seed $^{c}$ & 0 & $12.79^{\mathrm{a}}$ & $55.6^{\mathrm{b}}$ & $0.0114^{\text {bc }}$ \\
\hline
\end{tabular}

Remark: Values within a similar column followed by the same letter are not significantly different in accordance with the results of the $95 \%$ confident level by the Tukey test.

\section{Seed Storage Behaviour: the Effects of Seed Storage to Seedling Growth, Seed Viability and Seedling RGRs}

Seed storage may influence the seedling growth and seed viability. In this study, seedling growth were described by the seedling height and RGR (Table 5). The significance of seed storage were investigated statistically. Based on the analyses, seed storage treatments which combine storage methods and storage durations significantly influence the seedling growth and seed viability. Storage methods influence the seedling height at $P$ value of 0.011 , while storage durations significantly influence the seedling height at $\mathrm{P}$ value of 0.038 . There is an interaction between storage methods and storage durations to the seedling height which is showed by $\mathrm{P}$ value of 0.025 . Storage methods significantly influence the seed viability at $\mathrm{P}$ value of 0.00 while storage durations significantly influence the seed viability at $\mathrm{P}$ value of 0.0003 . Storage methods and storage durations are interacted to significantly influence the seed viability at $\mathrm{P}$ value of 0.000 . Storage methods influence the seedling RGR at $P$ value of 0.000 , while storage durations influence the seedling RGR at $\mathrm{P}$ value of 0.0004 . These two factors were interacted to each other in influencing the seedling RGR at $P$ value of 0.000 .

\section{Seedling Height}

The seedling growth of $P$. indicus is represented by the seedling height and RGR (Fig. 3. and Fig. 4). The seedling height of $P$. indicus varied among storage methods and storage durations (Fig. 3). Based on the statistical analysis, all treatments in storage methods and storage durations are significantly different among treatments compare to control (fresh seed with no storage). Seedling in storage durations under 3 months (1 and 2 months) has higher seedling height compare to that of control treatment. Figure 3 showed the increase and difference of seedling height of seedling with storage methods and durations. The seed stored at room temperature during one month (1RT) has 
the highest seedling height while the seed stored in sealed jar during 3 months (3SJ) has the lowest seedling height.

\section{Seedling RGR}

Figure 4 showed the increase and difference of seedling RGR of seeds with storage method and storage duration.

The seeds stored in sealed jar during 5 months $(5 \mathrm{SJ})$ had the highest seedling RGR, while the seed storage at cold temperature from one to 5 months (1CT-5CT) had the lowest seedling RGR.

\section{Seed Viability}

Figure 5 showed the difference of seedling viability in different seed storage methods and durations. The research results showed that the seed stored in sealed jar during 3 months (3SJ) has the highest seed viability (93.33\%), while the seed stored in sealed jar during 4 months (4SJ) has the lowest seed viability (43.33\%).

\section{Seed Storage Importance of $\boldsymbol{P}$. indicus}

Seedling recruitment of $P$. indicus compared with those of other species was presented in Table 6 .

The number of seedling of $P$. indicus were compare to seedling recruitment of other species based on the previous study. The number of $P$. indicus seedling in rainy season was lower rather than in dry season (Table 6). Additionally, the seedling coverage in rainy season was $4.53 \%$ while the seedling coverage in dry season was $8.5 \%$. The seedling coverage in dry season is higher than that in rainy season. A critically endangered species Saccarenia rubra have higher number of seedling in rainy season than in dry season. The abundant species of Attalea buttyracea have high seedling recruitment, while Betula alleghaniensis have quite high seedling recruitment. None sapling stage found growing in the garden ground based on the surveys indicated that $P$. indicus which grow in a garden has very low seedling establishment. The fruit and seed of $P$. indicus are available during the whole year. However, the seedling could be established only at appropriate conditions such as humidity or light intensity. Based on the result, $P$. indicus was reported to have lower seedling recruitments compared to those of two other abundant species. The seedling recruitment of $P$. indicus is higher in dry season, which is revealed not only by the number of seedling but also by the seedling coverage.

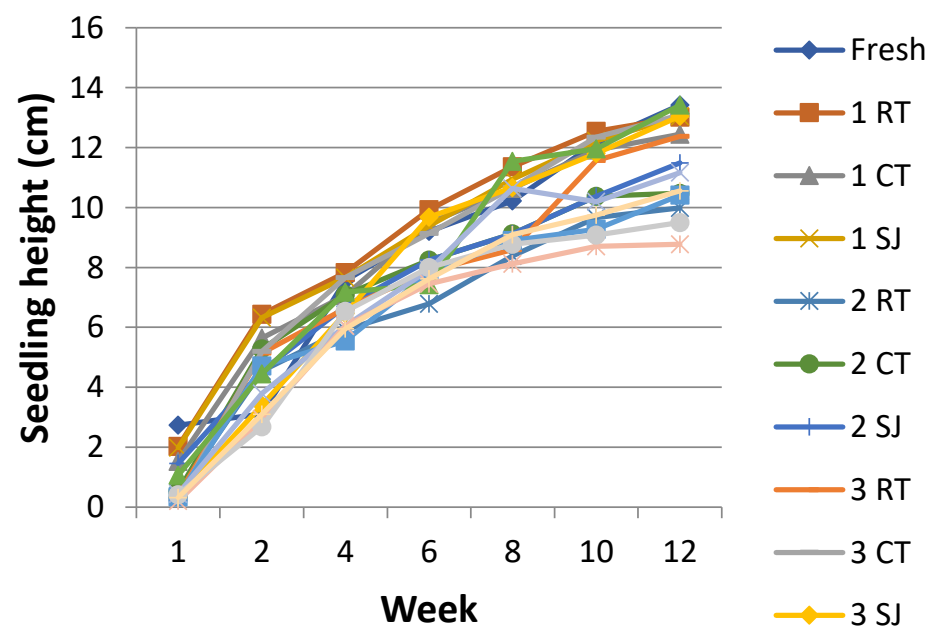

Figure 3. Seedling height of $P$. indicus in different storage method (room temperature, cold temperature and sealed jar) and duration (fresh seed until 5 months of seed storage).

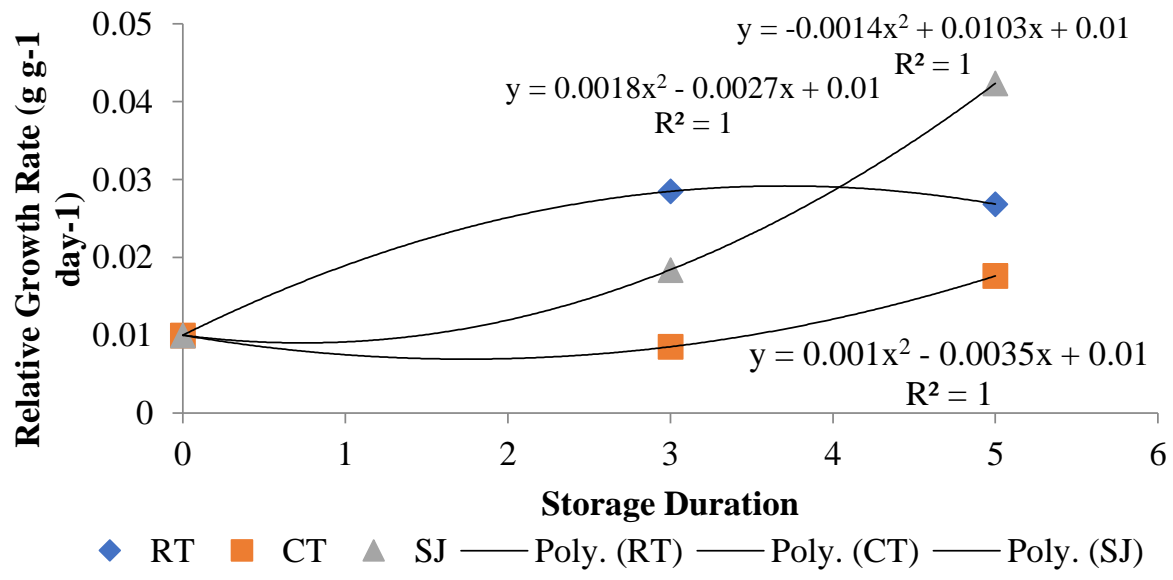

Figure 4. Relative Growth Rate of seedling of $P$. indicus in different storage methods i.e. room temperature (RT), cold temperature (CT) and sealed jar (SJ) and storage durations (fresh seed to stored during 5 months). 


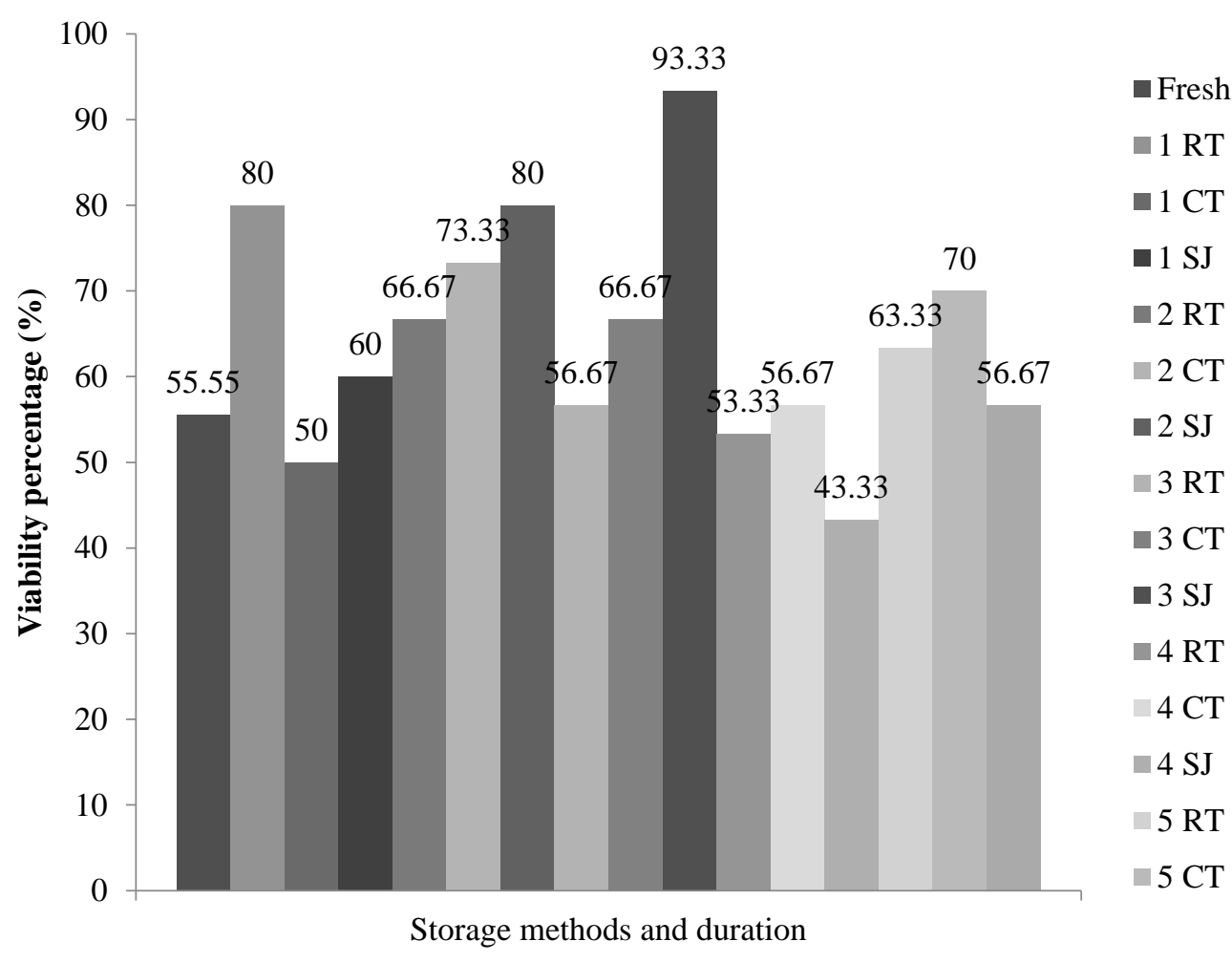

Figure 5. Seed viability of $P$. indicus in different storage methods (room temperature, cold temperature and sealed jar) and duration (fresh until 5 months).

Table 6. The comparison of the number of seedling between $P$. indicus in rainy and dry season and that of others plant species.

\begin{tabular}{|c|c|c|c|c|}
\hline \multirow[t]{2}{*}{ Species } & \multicolumn{2}{|c|}{ Season } & \multirow[t]{2}{*}{ Category } & \multirow[t]{2}{*}{ Sampling method } \\
\hline & $\begin{array}{l}\text { Rainy } \\
\text { season }\end{array}$ & Dry season & & \\
\hline Pterocarpus indicus (this study) & 4.3 & 5.3 & Low & Plot of $1 \mathrm{~m}^{2}$ \\
\hline $\begin{array}{l}\text { Saccarenia rubra (Chesser \& Brewer, } \\
\text { 2011) }\end{array}$ & 7 & 1 & Low & Per 100 seed sowed \\
\hline $\begin{array}{l}\text { Betula alleghaniensis (Houle, 1998) (on } \\
\text { average during } 4 \text { years) }\end{array}$ & 16 & 16 & Quite high & Plot of $1 \mathrm{~m}^{2}$ \\
\hline $\begin{array}{l}\text { Attalea buttyracea (Wright \& Dubber, } \\
\text { 2001) }\end{array}$ & 136 & 136 & High & Plot of $1 \mathrm{~m}^{2}$ \\
\hline
\end{tabular}

\section{Discussion}

Seeds are reproductive organs for plants consisted of embryos which bring genetic materials from the anchestor to its offsprings. Seeds has various characteristic depends on the plant strategy in seed dispersion. Seeds of dicot trees has several important component for plant dispersal which are embryo, cotyledon and seed coat. During maturity, embryo depends on the cotyledon in taking up the nutrients for growth. Generally, there are two types of seed based on their germination and moisture content, which are recalsitran and orthodox seed. Recalsitrant seeds cannot be dried without damage so they cannot conform to the viability equation which describe relations between longevity and air-dry seed storage environments. Orthodox seeds can be dried without damage to low moisture content at least to $2-6 \%$, over a wide range environments, their longevity increases with decreases in seed storage moisture content and temperature in a quantifiable and predictable way. The intermediate between these two seed types is intermediate which are more tolerant of desiccation than recalcitrants however is much more limited in tolerance than orthodox seeds. Intermediate seeds commonly lose viability more rapidly at low temperature (Roberts, 1973).

\section{Seed Storage Behaviour : the Effects of Seed Storage to Seedling Growth and Viability}

Seed storage behaviour refers to degree of desiccation tolerance and suitable environment of seed storage (Hong \& Eliis, 1996). The seed of $P$. indicus is reported as orthodox seed because the seed can be dried without damage to moisture content of $10-12.5 \%$ with the viability percentage between $43-93.3 \%$. The seed of $P$. indicus is mechanically dormant (Schmidt, 2000). Moreover, according to Turner et al. (2009), a seed which is physiologically dormant need at least 20-30 weeks to germinate under laboratory condition and more than 15 months under field condition especially in Astroloma xerophyllum. $P$ indicus germinated in 5-11 days after 
seeding and have new shoot emergence before 20 days after seeding (Table 2). It showed that the seed of this species mechanically but not physiologically dormant (Baskin \& Baskin in Guerant et al., 2004).

This study is to investigate the effect of seed storage to seedling growth and viability as parameters relate to the success of plant's life. Seed storage both using different storage methods and periods influenced the seedling height. Seedling height of seed stored at room temperature during 1-3 months is the highest among those of all treatments. The seedling RGR of seed stored in sealed jar during 4-5 months is the highest, while the seedling viability of seed stored in sealed jar is the highest among those of all treatments.

Moisture content is one of important physiological factors in maintaining seed germinability during storage. Different morphological and physiological characteristic cause optimal moisture content for seed storage which varies greatly among plant species and storage methods. Thus, the success of storage methods are mostly determined by moisture content. The seed of $P$. indicus is reported as orthodox seed. Because seed viability on moisture content of $10-12 \%$ varies from $43-90 \%$, the seed clasification of $P$. indicus into orthodox or intermediate is necessary to be confirmed. To confirm the seed clasification, it is necessary to study the seed viability in moisture content below $5 \%$.

According to Hong et al. (1998), orthodox species originate from environments adapted to drought condition in which desiccation tolerance of the seed is important for seed survival. There is a wide variation in moisture content of seed of $P$. indicus in this study (10-12.5\%). This variation may influence the seedling growth and seed viabilities. Seeds stored in room temperature have the highest seed height and viability, while the seeds stored in sealed jar have a lowest seed height and viability. The moisture content of seed stored at room temperature declined during the storage period from $12.5 \%$ to $10 \%$ in month 2 (see Table 3), while the moisture content of seed stored in sealed jar declined to $11.48 \%$ in month 4 . It indicated that seed with moisture content around $10 \%$ have high seed height and viability. Furthermore, the seeds stored at room temperature and sealed jar have high RGR while the seed stored at cold temperature have the lowest RGR. Chilling temperature caused the moisture content decline sharply from $12.43 \%$ to $10.11 \%$. It suggested that the sharp decline of seed moisture content until $10 \%$ caused the low seedling growth.

The seedling RGR experienced sharp decline at the storage of cold temperature. Cold temperature influence the seed longevity either of orthodox or intermediate seed (Hong et al., 1998). Storage temperature at below $10^{\circ} \mathrm{C}$ reduce dry seed longevity with $7-10 \%$ of moisture content. The storage method in this study used cold temperature at below $10^{\circ} \mathrm{C}\left(-15^{\circ} \mathrm{C}\right)$. Therefore, the seed of $P$. indicus which included in orthodox seed with $10 \%$ moisture content, have high reduction in its longevity and may in its seed vigor.

The seedling RGR of $P$. indicus fresh seed was $0.01 \mathrm{~g}$ $\mathrm{g}^{-1}$ day $^{-1}$. It increased after 3 month of storage in sealed jar and at room temperature. In contrast to both treatments, the RGR of seedling from the seed stored at cold temperature decreased in 3 month storage. The low seedling RGR of $P$. indicus stored at cold temperature was suggested as the effect of the low temperature which cause sharp decline of moisture content. Thus, the seeds of this species better to be stored at cold temperature of up to $10^{\circ} \mathrm{C}$ which predictably will cause the moisture content decrease gradually. The gradual reduction of moisture content is resulted by the storage in sealed jar (from $12.5 \%$ to $11.48 \%$ ) because it showed the highest seedling RGR in the storage during 5 months (5SJ) and the highest seed viability when it is stored in sealed jar during 3 months (3SJ).

The difference of moisture content in seed storage commonly influence the seed storage duration especially in orthodox and intermediate seed (Hong et al., 1998). For orthodox seed, the lower moisture content is commonly more advisable for longterm storage. For example, Dipterocarpus intricatus and Dipterocarpus tuberculatus were dried to about $12 \%$ moisture content for storage in the shorterm and $8 \%$ in the longterm. However, in many other species such as $D$. alatus, the seed is better to be stored for longterm in $12 \%$ moisture content (Tompsett, 1987). For long term storage and low cost consideration, $P$. indicus is better to be stored at room temperature or in sealed jar at room temperature until 5 months at around $11 \%$ moisture content.

The Relative Growth Rate (RGR) is the plant's ability to produce biomass as the result of assimilation per unit of dry weight per time which expressed in $\mathrm{g} \mathrm{g}^{-1}$ day $^{-1}$. RGR of seedlings is a key attribute for the performance of species in their natural habitats. The RGR of hypogeal seedlings is lower than epygeal species because it tends to have a slower development rate, and most of large seeded species tend to be hypogeal. The RGR in large seed is lower because the metabolic effect predicts a negative relationship between seed size and RGR during the early stages (Poorter \& Rose, 2005; Quero et al., 2007). Poorter and Rose (2005) stated that the weight of small seeds is $<0.1 \mathrm{~g}$ and large seed is $>0.1 \mathrm{~g}$. The average weight of $P$. indicus seed is $0.079 \mathrm{~g}$ and is categorized as a small seed. The RGR of $P$. indicus tend to be higher rather than that of other species with a larger seed. The difference between small and large seeded plants is closely parallel with shadetolerant species based on the growth rate, morphological and physiological traits.

Plant RGR was affected by the interaction of both treatments i.e. storage duration and storage method. Based on Lugo and Leopoled (1992) in the study about maize seed, the decline vigor of the seed under conditions of slightly accelerated aging is related to the decline of several sugars content in the embryo, especially, a decline in raffinose. Storage at low cold temperatures resulted low growth compared with other two treatments. Seed stored at cold temperature caused the seedling of $P$. indicus grows dwarfed. Moreover, its cotyledon, as a source of food reserves in the seeds, did not appear and some decayed rapidly and resulting in low RGR. This indicates that the longer duration of seed storage resulted in abnormal growth of the seedling of $P$. indicus because of the food reserves in the seeds was decreased during seed storage. 


\section{Seed Storage Importance of $\boldsymbol{P}$. indicus}

Seed storage importance of $P$. indicus for seed conservation was studied by analyzing seedling recruitment. Recruitment is the process by which new individuals found a population or are added to an existing population. Although recruitment may refer to clonal offspring, by far the most common means of recruitment is by seedlings. Seedling recruitment includes three basic processes: seed germination, seedling survivorship, and seedling growth. Seedling is a plant growth stage which represent the interface between the seed and the developing plant, and as a transitional life cycle stage (Kitajima \& Fenner, 2000). Seedling recruitment varies widely across plants species and communities. A stable population is maintained if one reproductive individual is replaced by one successfully recruited offspring. Because seedlings are commonly subject to the highest mortality rates of any stage in the plant life cycle, observing seedling of vulnerable plant species will be meaningful for their conservation study.

Although the fruit and seed of $P$. indicus is available a whole year, the importance of seed storage should be studied by investigate the seedling establishment in the nature. Because, the seedling could be established only at appropriate conditions such as humidity or light intensity. Based on the result, $P$. indicus was reported to have low seedling recruitments compared to those of two other abundant species (Table 6). Moreover, the seedling recruitment of $P$. indicus is higher in dry season, which is

\section{References}

Baskin, C. C., \& Baskin, J. M. (2004). in Guerrant Jr, E. K. Havens, and Mike Maunder. 2004. Ex-situ Plant Conservation: supporting species survival in the wild. Island Press, Washington DC. 162 166

Bonfil, C. (1998). The effects of seed size, cotyledon reserves, and herbivory on seedling survival and growth in Quercus rugosa and Q. laurina (Fagaceae). American Journal of Botany, 85(1), 79-87.

Chesser, J. D., \& Brewer, J. S. (2011). Factors influencing seedling recruitment in a critically endangered pitcher plant, Saraccenia rubra spp. Alabamensis. Endangered Species Research, 13, 245 252

Eriksson, O., \& Ehrlén, J. (2008). Seedling Ecology and Evolution. Cambridge University Press.

Guerrant, Jr., Havens, E. K., \& Maunder, M. (2004). Ex-situ Plant Conservation: supporting species survival in the wild. Island Press, Washington DC.

Hoffmann, W. A., \& Poorter, H. (2002). Avoiding bias in calculations of relative growth rate. Annals of Botany, 90(1), 37-42.

Hong, T. D., \& Ellis, R. H. (1996). A protocol to determine seed storage behaviour. IPGRI Technical Buletin No. 1. Via delle Sette Chiese 142, Rome.

Hong, T. D., Linington, S., \& Ellis, R. H. (1998). Compendium of information on seed storage behaviour volume I A-H. The Royal Botanic Gardens, Kew. 3-36.

Houle, G. (1998). Seed dispersal and seedling recruitment of Betula alleghaniensis: spatial in consistency in time. Ecology, 79(3), 807818.

Kitajima, K., \& Fenner, M. (2000). Ecology of seedling regeneration. In Fenner M, editor. Seeds: the ecology of regeneration in plant also revealed not only by the number of seedling but also by the seedling coverage. It indicated that the seedling requires dry environment to grow and leaf expansion. Because the fruit and seed production of this species is higher in dry season than in rainy season (Table 1), it is suggested to harvest the seed during the dry season then store it during the rainy season.

The study result also showed that there is no sapling stage in the garden ground either during rainy or dry season. It showed that the seedling establishment of this species is low. The seedling of this species likely requires an open environment to grow, thus dense tree stands in the garden or forest inhibited the growth of seedling to sapling stage. Bonfil (1988) stated that the probabilities of seedling survival after detachment of the cotyledons may be affected by the amount of reserves originally available to the seedling. Herbivory, frost, drought, and pathogens are other challenges facing a seedling early in its life. The ability to cope with them is likely affected by the presence or absence of cotyledons, the size of the seed from which it originated, and the time elapsed since germination. According to Chesser and Brewer (2011), seedling recruitment of a plant species in rainy season and soil is commonly higher than in dry environment because high soil moisture can provide suitable environment for seedling survivorship. The study result showed that seed production and seedling establishment of this species tend to grow faster in open shaded area and in relative dry environment than in shaded and wet environment.

communities. Wallingford: $\mathrm{CAB}$, International.

Lugo, B. I., \& Leopold, A. C. (1992). Changes in soluble carbohydrates during seed storage. Plant Physiology, 98, 1207-1210.

Orwa, C., Mutua, A., Kindt, R., Jamnadass, R., \& Anthony, S. (2009). Agroforestree Database: a tree reference and selection guide version 4.0. $\quad$ Retrieved from http://www.worldagroforestry.org/sites/treedbs/treedatabases.asp

Poorter, L., \& Rose, S. A. (2005). Light-dependent changes in the relationship between seed mass and seedling traits: a metaanalysis for rain forest tree species. Oecologia, 142, 378-387.

Quero, J. L., Villar, R., Maranon, T., Zamora, R., \& Poorter, L. (2007). Seed-mass effects in four mediterranean Quercus species (Fagaceae) growing in contrasting light environments. American Journal of Botany, 94(11), 1795-1803.

Roberts, E. H. (1973). Predicting the storage life of seeds. Seed Science and Technology, 1, 499-514.

Schmidt, L. (2000). Guide to Handling of Tropical and Subtropical Forest Seed. PT. Gramedia Jakarta.

Thomsom, L. A. J. (2006). Species profile for Pasific Island Agroforestry: Pterocarpus indicus. Retrieved from www.traditionaltree.org.

Tompsett, P. B. (1987). Desiccation and storage studies on Dipterocarpus seeds. Annual Applied Biology, 110, 371-379.

Turner, S. R., Commander, L. E., Baskin, J. M., Baskin, C. C., \& Dixon, K. W. (2009). Germination behaviour of Astroloma xerophyllum (Ericaceae), a species with woody indehiscent endocarps. Botanical Journal of The Linnaean Society, 160, 299-311.

Wright, S. J., \& Duber, H. C. (2001). Poacher and forest fragmentation alter seed dispersal, seed survival, and seedling recruitment in the Palm Attalea buttyracea with implications for tropical tree diversity. Biotropica, 33(4), 583-595. 